\title{
Profile of sugammadex for reversal of neuromuscular blockade in the elderly: current perspectives
}

REVIEW

\author{
Michele Carron \\ Francesco Bertoncello \\ Giovanna leppariello \\ Department of Medicine, \\ Anesthesiology, and Intensive Care, \\ University of Padova, Padua, Italy
}

This article was published in the following Dove Press journal:
Clinical Interventions in Aging

\begin{abstract}
The number of elderly patients is increasing worldwide. This will have a significant impact on the practice of anesthesia in future decades. Anesthesiologists must provide care for an increasing number of elderly patients, who have an elevated risk of perioperative morbidity and mortality. Complications related to postoperative residual neuromuscular blockade, such as muscle weakness, airway obstruction, hypoxemia, atelectasis, pneumonia, and acute respiratory failure, are more frequent in older than in younger patients. Therefore, neuromuscular blockade in the elderly should be carefully monitored and completely reversed before awakening patients at the end of anesthesia. Acetylcholinesterase inhibitors are traditionally used for reversal of neuromuscular blockade. Although the risk of residual neuromuscular blockade is reduced by reversal with neostigmine, it continues to complicate the postoperative course. Sugammadex represents an innovative approach to reversal of neuromuscular blockade induced by aminosteroid neuromuscular-blocking agents, particularly rocuronium, with useful applications in clinical practice. However, aging is associated with certain changes in the pharmacokinetics of sugammadex, and to date there has been no thorough evaluation of the use of sugammadex in elderly patients. The aim of this review was to perform an analysis of the use of sugammadex in older adults based on the current literature. Major issues surrounding the physiologic and pharmacologic effects of aging in elderly patients and how these may impact the routine use of sugammadex in elderly patients are discussed.
\end{abstract}

Keywords: sugammadex, aging, elderly, neuromuscular blockade, rocuronium, anesthesia, safety

\section{Introduction}

Between now and 2030, every country will experience population aging, a trend that is both pronounced and historically unprecedented. Over the past six decades, countries of the world experienced only a slight increase in the proportion of people aged $\geq 60$ years: from $8 \%$ to $10 \% .^{1}$ In the next four decades, this group is expected to rise to $22 \%$ of the total population, an increase from 800 million to 2 billion people. ${ }^{1}$ This will have a major impact on the practice of anesthesia in future decades. Approximately $50 \%$ of elderly patients will require anesthesia for a surgical intervention, and thus the population of patients presenting for elective surgery will be sicker and at greater risk of perioperative complications. ${ }^{2,3}$

Several factors may contribute to increased postoperative morbidity and mortality in elderly persons. Aging results in physiologic changes within all organ systems, with changes in the respiratory, cardiovascular, and renal systems being of particular importance to anesthesia. Furthermore, aging is accompanied by an increased risk of chronic
Correspondence: Michele Carron Department of Medicine, Anesthesiology, and Intensive Care, University of Padova, 267 Via Cesare Battisti, Padua 35 I I, Italy

Tel +390498213090

Fax +39049875 4256

Email michele.carron@unipd.it
Clinical Interventions in Aging 2018:13 |3-24

13 
disease, which may further limit organ function and accelerate the age-related decrease in reserve capacity of the affected organs. ${ }^{4}$ Drug disposition, metabolism, and excretion may be altered in elderly patients as a result of several factors, including changes in pharmacokinetics and pharmacodynamics, alterations in receptor sensitivity, and impairment of the body's normal homeostatic mechanisms. ${ }^{2}$ Knowledge of these age-related factors will allow anesthesiologists to maximize perioperative outcomes, while maintaining safety and efficiency. ${ }^{3}$

Incomplete recovery from neuromuscular blockade (NMB) after anesthesia and surgery continues to be a common problem in the postanesthesia care unit (PACU). Despite routine use of anticholinesterase reversal agents, $20 \%-40 \%$ of patients continue to arrive in the PACU with objective evidence of residual NMB. ${ }^{5,6}$ Numerous clinical studies have documented that incomplete recovery from NMB is associated with a variety of adverse events in the early postoperative period, including muscle weakness, airway obstruction, hypoxemic episodes, postoperative respiratory complications (eg, atelectasis, pneumonia), and respiratory failure. ${ }^{5,6}$ In a prospective, cohort-matched observational study, Murphy et al found that the incidence of postoperative residual NMB was $57.7 \%$ in elderly patients, but only $30 \%$ in younger patients (difference $-27.7 \%, 99 \%$ CI $-41.2 \%$ to $-13.1 \% ; P<0.001) .{ }^{7}$ Muscle weakness, airway obstruction, hypoxemic events, postoperative pulmonary complications, and increased PACU and hospital lengths of stay were observed more frequently in the elderly $(P<0.01$ for all). ${ }^{7}$ In a prospective cohort study of 599 adult patients who received NMB agents (NMBAs) during general anesthesia, Stewart et al found that adverse respiratory events in the PACU were more frequent in patients with residual NMB $(P=0.033)$, which was significantly associated with age (adjusted relative risk 1.17, 95\% CI 1.06-1.29 per 10 -year increase). ${ }^{8}$ Therefore, the elderly have an increased risk of postoperative residual NMB and associated adverse outcomes compared with younger adults. ${ }^{7,8}$

Altered pharmacokinetics of NMBAs in elderly patients lead to prolonged duration of action of these drugs and delayed recovery from NMB compared to younger subjects. Although this mainly applies to aminosteroid NMBAs, benzylisoquinoline NMBAs may also require dose adjustment to prevent residual NMB. Therefore, NMB in the elderly should be routinely monitored and completely reversed before awakening patients at the end of anesthesia..$^{9-12}$ Differences between young and elderly patients with respect to antagonism of NMB by acetylcholinesterase inhibitors have been reported. Young et al noted prolonged duration of action of neostigmine in aged patients $(32 \pm 10$ vs $11 \pm 2$ minutes, $P<0.05),{ }^{13}$ confirming previous data $(42 \pm 10$ vs $13 \pm 14$ minutes in older vs younger patients, $P<0.01) .{ }^{14}$ These reflect changes observed with aging, such as a decrease in the initial volume of distribution in older compared to younger patients $(0.1 \pm 0.4$ vs $0.068 \pm 0.018 \mathrm{~L} / \mathrm{kg}, P<0.05)$, which allows a greater concentration of neostigmine to be initially available to act at the NM junction. ${ }^{13,14}$ However, this effect is balanced by the prolonged duration of action of NMBAs in the elderly, so the risk of residual NMB is not avoided in the elderly after administering acetylcholinesterase inhibitors. Although reversal with neostigmine decreases the risk of residual NMB, it continues to complicate the postoperative course, depending on the patient's age. ${ }^{7,8}$

Sugammadex represents an innovative approach to reversal of NMB induced by aminosteroid NMBAs, particularly rocuronium, with important implications for clinical practice. ${ }^{15,16}$ In a recent meta-analysis, Carron et al found that compared to neostigmine, sugammadex was associated with faster reversal of NMB $(P<0.0001)$ and lower risk of postoperative residual NMB after extubation (OR 0.05, 95\% CI $0.01-0.43 ; P=0.0068) .{ }^{15}$ Furthermore, compared to neostigmine, sugammadex was associated with significantly lower likelihood of global (OR 0.47, 95\% CI 0.34-0.66; $P<0.0001$ ), respiratory (OR $0.36,95 \% \mathrm{CI} 0.14-0.95 ; P=0.0386)$, and cardiovascular (OR $0.23,95 \%$ CI $0.08-0.61 ; P=0.0036$ ) adverse events, as well as postoperative weakness (OR 0.45, 95\% CI 0.21-0.97; $P=0.0409) .{ }^{15}$ Together, these benefits produce faster discharge of patients to the surgical ward after general anesthesia with sugammadex compared to neostigmine. ${ }^{16}$

The aforementioned evidence is derived from studies that have often excluded elderly patients. To date, there has been no thorough evaluation of the use of sugammadex in elderly patients. The aim of this review is to analyze the use of sugammadex in this older population based on the existing literature.

\section{Physiologic and pharmacologic effects of aging}

The aging process results in progressive functional decline in all major organ systems. Until 60 years of age, both basal organ function and physiologic reserve (difference between basal and maximal organ function) are well maintained. Physiologic reserve subsequently diminishes, with a large difference in the rate of age-related decline. ${ }^{17}$ Age-related physiologic changes may affect both the pharmacokinetics and pharmacodynamics of drugs commonly used for general anesthesia (Table 1). 
Table I Main age-related physiologic changes in the elderly and implications for anesthetic management

\begin{tabular}{|c|c|c|}
\hline Body component & Changes & Anesthetic implications \\
\hline Nervous system & $\begin{array}{l}\downarrow \text { White and gray matter in the brain (atrophy) } \\
\downarrow \text { Cerebral blood flow }\end{array}$ & $\begin{array}{l}\uparrow \text { Sensitivity to anesthetic drugs (eg, propofol, benzodiazepines, } \\
\text { inhalational agents, ketamine, opioids) } \\
\downarrow \text { Delivery and longer onset of clinical effects of anesthetic agents }\end{array}$ \\
\hline Respiratory system & $\begin{array}{l}\downarrow \text { Lung function } \\
\downarrow \text { Respiratory responses to hypoxia and hypercapnia } \\
\downarrow \text { Respiratory muscle strength }\end{array}$ & $\begin{array}{l}\uparrow \text { Onset time of inhalational agents } \\
\uparrow \text { Sensitivity to anesthetic drugs (eg, opioids, benzodiazepines) } \\
\uparrow \text { Sensitivity to NMBAs }\end{array}$ \\
\hline $\begin{array}{l}\text { Cardiovascular } \\
\text { system }\end{array}$ & $\downarrow$ Cardiac output & $\begin{array}{l}\uparrow \text { Onset time of anesthetic drugs (eg, propofol, inhalational agents, } \\
\text { NMBAs, sugammadex) }\end{array}$ \\
\hline Liver & $\begin{array}{l}\downarrow \text { Liver function } \\
\downarrow \text { Hepatic blood flow } \\
\downarrow \text { Phase I metabolism (eg, oxidation, reduction, } \\
\text { hydrolysis) }\end{array}$ & $\begin{array}{l}\downarrow \text { Clearance of anesthetic drugs eliminated by the liver } \\
\text { (eg, aminosteroid NMBAs) }\end{array}$ \\
\hline Kidney & $\begin{array}{l}\downarrow \text { Renal function } \\
\downarrow \text { Glomerular filtration rate } \\
\downarrow \text { Renal blood flow }\end{array}$ & $\begin{array}{l}\downarrow \text { Clearance of anesthetic drugs eliminated by the kidney (eg, NMBAs, } \\
\text { sugammadex) }\end{array}$ \\
\hline Muscle & $\begin{array}{l}\downarrow \text { Muscle mass (atrophy) } \\
\downarrow \text { Muscle blood flow }\end{array}$ & $\downarrow$ Delivery of anesthetic drugs (eg, NMBAs, sugammadex) \\
\hline Plasma proteins & $\begin{array}{l}\downarrow \text { Protein binding (eg, albumin) } \\
\downarrow \text { Activity (eg, plasma cholinesterases) }\end{array}$ & $\begin{array}{l}\uparrow \text { Potency of anesthetic drugs (eg, propofol) } \\
\uparrow \text { Duration for anesthetic drugs (eg, succinylcholine, } \\
\text { benzylisoquinoline NMBAs) }\end{array}$ \\
\hline Body composition & $\begin{array}{l}\downarrow \text { Total body water } \\
\downarrow \text { Lean body mass } \\
\uparrow \text { Body fat }\end{array}$ & $\begin{array}{l}\uparrow \text { Potency of anesthetic drugs (eg, propofol, benzodiazepines, opioids) } \\
\uparrow \text { Duration for lipophilic anesthetic drugs (eg, benzodiazepines, } \\
\text { inhaled anesthetics) }\end{array}$ \\
\hline
\end{tabular}

Note: Data from these studies., ${ }^{9} 12,17-34$

Abbreviation: NMBAs, neuromuscular blocking agents.

\section{Cerebral effects of aging}

Brain atrophy occurs with increasing age. Evaluating 201 healthy adults aged $\geq 55$ years over 6 years, Enzinger et al found that the mean annual brain-volume change was $-0.4 \% \pm 0.29 \%$ (range -1.47 to $0.32 \%$, women $-0.39 \% \pm 0.26 \%$ vs men $-0.41 \% \pm 0.31 \% ; P=0.76) .{ }^{18}$ Furthermore, increased age was correlated with an accelerated rate of brain atrophy: annual brain-volume change in subjects aged $65-75$ years was twice as high as that of subjects aged 50-54 years $(-0.55 \% \pm 0.29 \%$ vs $-0.28 \% \pm 0.23 \%, P<0.0001)$. While cerebral atrophy increases, cerebral perfusion decreases after 60 years of age. Using the ${ }^{15} \mathrm{O}$ steady-state inhalation method and positron-emission tomography in a group of 34 healthy volunteers aged 22-82 years, Leenders et al found that regional cerebral blood flow, oxygen utilization, and blood volume in "pure" gray- and white-matter regions decreased with increasing age by $\sim 0.5 \%$ per year. ${ }^{19}$ These changes lead to a decrease in the rate of delivery of most anesthetic agents to the nervous system, slower brain uptake, slower bloodbrain equilibration, and slower onset of clinical effects. ${ }^{9,20}$

\section{Respiratory effects of aging}

Age-related deterioration of pulmonary function does not produce significant symptoms in unstressed individuals. ${ }^{17}$ The main changes in the respiratory system with aging include decreased lung elasticity, chest-wall compliance, vital capacity, alveolar surface area, and diffusion capacity, as well as increased residual volume, dead space, and ventilation-perfusion mismatch. ${ }^{9}, 17,21$ Respiratory responses to hypoxia and hypercapnia are markedly diminished in older patients. ${ }^{17,20,21}$ Respiratory muscle strength consistently declines with age, further increasing the work of breathing. ${ }^{17}$ All of these changes increase the risk of gas-exchange abnormalities in the perioperative period and enhance sensitivity to the respiratory-depressant effects of anesthetics and opioid analgesics. Muscle weakness poses additional risks of the development of postoperative respiratory complications in elderly patients in the setting of incomplete recovery from NMB., ${ }^{9}, 17,20,21$

\section{Cardiovascular effects of aging}

Aging also produces alterations in cardiovascular physiology, and older patients have an inevitable and progressive loss of functional reserve. ${ }^{9,17,20,22}$ Myocardial stiffness and increased arterial stiffness are the main cardiovascular changes. They lead to increased systolic and diastolic blood pressure, left ventricular hypertrophy, and prolonged relaxation of the left ventricle in diastole. Myocardial work increases. Fibrosis of the cardiac skeleton, associated with calcification at the base of the aortic valve, is also present 
in older adults. ${ }^{9,17,20,22}$ Cardiac output at rest is decreased in older individuals, and maximal heart rate also decreases with aging. In healthy, older individuals, increases in cardiac output are primarily accomplished by increasing end-diastolic volume and by increasing stroke volume at a similar ejection fraction. ${ }^{17}$ Intrinsic function of both the sympathetic and parasympathetic nervous systems decreases, and reactivity of baroreceptors and chemoreceptors also decreases with aging, leading to a reduced response to postural changes and hypotension, as well as an increase in circulating catecholamines. ${ }^{9,17,20,22}$ These changes set the stage for isolated systolic hypertension, diastolic dysfunction, heart failure, atrioventricular conduction defects, and aortic-valve calcification, all diseases found in the elderly. Together, age-related cardiovascular changes lead to decreased cardiovascular capacity in the elderly, explaining the increased cardiodepressant effects of many anesthetic drugs and the risk of rhythm changes or dysrhythmias after reversal of NMB with neostigmine, often given in association with muscarinic receptor-antagonist drugs, such as atropine or glycopyrrolate. ${ }^{9,17,20,22}$

\section{Renal effects of aging}

Renal function decreases with age. This is caused by loss of renal parenchyma ( $\sim 10 \%$ per decade of increasing age), ${ }^{23}$ decreased renal blood flow (10\% decline per decade),${ }^{24}$ and decreased glomerular filtration rate $(0.4-1.02 \mathrm{~mL} / \mathrm{min}$ per year), all of which contribute to a $30 \%-50 \%$ decrease in creatinine clearance between the ages of 20 and 90 years. ${ }^{25}$ Despite this decline in renal function, serum creatinine levels remain within the normal range, because of reduced production of creatinine, a product of muscle catabolism. Loss of muscle mass occurs at a rate similar to the rate of decrease in glomerular filtration rate. ${ }^{17,20}$ As a consequence, drugs (or metabolites), also including anesthetics and muscle relaxants, that are primarily eliminated via the renal system have longer half-lives and reach higher peak levels, possibly leading to toxicity. ${ }^{9,17}$

\section{Hepatic effects of aging}

Liver mass decreases by $20 \%-40 \%$ during the typical human life span, ${ }^{26}$ with a concomitant decline in hepatic blood flow of $10 \%$ per decade ${ }^{27}$ and a moderate decline in phase I metabolism of certain drugs. ${ }^{26}$ Phase I reactions largely depend on the action of cytochrome P450 enzymes, which modify drugs by oxidation, reduction, or hydrolysis to form metabolites. ${ }^{9,17,26}$ Phase II reactions are involved in the subsequent elimination of these metabolites by attaching small polar endogenous molecules (acetyl, methyl, sulfur, or glucuronide groups) to form water-soluble compounds. This process, called conjugation, is mediated by a number of enzymes, ${ }^{9,17,26}$ and is generally not affected by age. ${ }^{9}$ Anesthesiologists should thus be aware of possible age-related effects on phase I reactions, leading to reduced metabolism of agents eliminated by the hepatic system (eg, aminosteroid NMBAs). ${ }^{9,17}$

\section{Muscle effects of aging}

Loss of skeletal muscle strength is a commonly recognized consequence of aging. Average reported age-related decreases in strength are $20 \%-40 \%$ for both men and women in both proximal and distal muscles. ${ }^{28,29}$ Longitudinal studies, with some exceptions, have reported somewhat-greater losses of strength over time ( $1 \%-3 \%$ per year) compared with crosssectional studies. ${ }^{28,29}$ Although age-associated decreases in strength per unit muscle mass (ie, muscle quality) may play a role, the majority of strength loss can be accounted for by decreased muscle mass of $\sim 40 \%$ between the ages of 20 and 60 years $^{29}$ and nearly $50 \%$ between the ages of 20 and 90 years. ${ }^{30}$ Age-related loss of muscle mass appears to be fairly consistent, occurring at a rate of approximately $1 \%-2 \%$ per year after 50 years of age. ${ }^{30}$ This loss is attributed to a decrease in both the number and size of skeletal muscle fibers. ${ }^{29,30}$

Aging is also associated with decreased muscle blood flow and vascular conductance in the elderly. ${ }^{12,31}$ Vascular function changes with aging include impaired endothelial function (eg, impaired formation and activation of nitric oxide) and altered reactivity of vascular smooth muscle to sympathetic activity. Age-related structural and functional alterations in the vascular system may explain age-associated reductions in muscle blood flow. ${ }^{31}$ These changes may influence the delivery of drugs to the muscle end plate and thereby contribute to delayed onset and longer duration of action of most NMBAs, as well as a greater risk of residual $\mathrm{NMB}$, in the elderly. ${ }^{31}$

\section{Pharmacology in the elderly Pharmacodynamic effects of aging}

The effect of age on drug sensitivity varies with the drug studied and the response measured. Advancing age is associated with increased sensitivity to the central nervous system effects of benzodiazepines; propofol, which requires a $40 \%-50 \%$ lower dose in patients aged $>65$ years; inhalational anesthetic agents; opioids, especially remifentanil; and local anesthetics. ${ }^{17,32}$ In the field of NM pharmacology, possible changes in receptor biological features (eg, ligand 
affinity and kinetics), perhaps occurring simultaneously with altered blood flow to muscles, ${ }^{12,17}$ has been suggested to occur in elderly patients. ${ }^{33,34}$ These changes involve slower release of NMBAs from receptors, delayed recovery of receptors, and possibly altered receptor expression at the NM junction. ${ }^{33,34}$

\section{Pharmacokinetic effects of aging Distribution}

In general, the volume of distribution of a drug and the plasma concentration produced by a given dose are inversely related. With increasing age, lean body mass and total body water decrease; therefore, hydrophilic drugs have a smaller volume of distribution and thus higher plasma concentration compared with those of younger individuals. Consequently, the effects of hydrophilic drugs will increase. Conversely, elderly patients tend to have a higher percentage of body fat. As a result, lipophilic drugs will have a higher volume of distribution in the elderly, which may lead to more extensive redistribution and a longer elimination half-life of lipophilic drugs. ${ }^{9,12}$

The volume of distribution of a drug is also influenced by such factors as protein binding (only unbound drug can be distributed), $\mathrm{pH}$, molecular size, and solubility. Most anesthetic drugs bind to plasma proteins, primarily albumin. Therefore, the free fraction and overall free drug concentration are inversely related to albumin concentration. Increasing the percentage of unbound drug increases the amount of drug available to produce an effect. Plasma albumin concentration tends to decrease with age, and structural protein changes occur with age that lead to decreased efficiency of albumin binding, to as little as $20 \%$ by the age of 70 years. ${ }^{9,12}$

\section{Metabolism and excretion}

The aging process affects drug metabolism in three main ways. First, reduced hepatic blood flow delivers the drug to the liver at a slower rate. Second, decreased liver mass reduces overall hepatic function. Finally, the liver's intrinsic metabolic activity is decreased..$^{9,12,17}$ The elimination of many drugs from the body occurs primarily via renal excretion. The half-life of these drugs increases as renal function decreases. ${ }^{9,12,17}$

\section{Pharmacodynamic and pharmacokinetic properties of sugammadex}

Sugammadex (previously Org 25969) is a modified $\gamma$-cyclodextrin with a circular structure containing eight adjoining glucose molecules. The diameters of the inner and outer rims of unmodified $\gamma$-cyclodextrin are approximately 0.75 and $0.85 \mathrm{~nm}$, respectively. Modifications to the parent molecule involve adding side chains to extend the cavity to $\sim 1.1 \mathrm{~nm}$ and adding negatively charged groups at the end of the side chains to enhance binding. Therefore, the drug is modified to better accommodate the four hydrophobic steroidal rings of rocuronium (or vecuronium) and to enhance electrostatic binding to the positively-charged quaternary nitrogen of rocuronium (or vecuronium). ${ }^{35,36}$

After injection, sugammadex encapsulates and inactivates unbound rocuronium (or vecuronium) by forming tight $\left(\mathrm{K}_{\mathrm{a}}\right.$ $1.05 \times 10^{7} \mathrm{~mol} / \mathrm{L} ; \mathrm{K}_{\mathrm{d}} \sim 0.1 \mathrm{mmol} / \mathrm{L}$ ) water-soluble complexes at a 1:1 ratio. In so doing, sugammadex creates a concentration gradient favoring movement of rocuronium (or vecuronium) from the NM junction into the plasma, which quickly reverses rocuronium- (or vecuronium)-induced NMB. ${ }^{35,36}$

In healthy adult volunteers, renal excretion of unchanged drug has been observed as the primary route of elimination for sugammadex (Table 2). The majority ( $>90 \%$ ) of a dose of sugammadex is excreted within 24 hours of administration. Sugammadex is primarily (96\%) excreted in the urine, predominantly ( $\geq 95 \%$ ) as unchanged drug; excretion in the feces or expired air is minimal $(0.02 \%) .{ }^{35-37}$ Sugammadex also increases the amount of rocuronium excreted unchanged in the urine. ${ }^{35-37}$ Administration of rocuronium and sugammadex 2 or $4 \mathrm{mg} / \mathrm{kg}$ (doses recommended for reversal of moderate or deep rocuronium-induced NMB in clinical practice, respectively) was associated with a two- to threefold increase in urinary excretion of unchanged rocuronium in the first 24 hours compared with rocuronium plus placebo in healthy volunteers ( $32 \%$ or $44 \%$ vs $14 \%$ of the administered dose). ${ }^{36}$ The effect of sugammadex on urinary excretion of rocuronium appears to be dose dependent. ${ }^{36}$

\section{Physiologic and pharmacologic effects of aging on sugammadex \\ Efficacy and safety}

Some case reports and few clinical studies have evaluated the efficacy and safety of sugammadex in elderly patients ${ }^{38-49}$ (Table 3). McDonagh et al conducted a parallel-group, comparative, open-label study evaluating sugammadex $2 \mathrm{mg} / \mathrm{kg}$ administered for reversal of moderate rocuronium-induced NMB in 150 patients undergoing intravenous or inhalational general anesthesia. They compared 48 younger adults (aged 18-64 years), 62 elderly adults (aged 65-74 years), and 40 old-elderly adults (aged $\geq 75$ years). ${ }^{45}$ The geometric mean time $(95 \% \mathrm{CI})$ from sugammadex administration to recovery of train-of-four (TOF) ratio to 0.9 increased with 
Table 2 Pharmacokinetic characteristics, chemical properties, and physical properties of rocuronium and sugammadex

\begin{tabular}{|c|c|c|c|}
\hline Pharmacological aspects & Parameters & Rocuronium $^{a}$ & Sugammadex ${ }^{b}$ \\
\hline \multirow[t]{8}{*}{ Pharmacokinetic } & $\begin{array}{l}\text { Volume of distribution } \\
\text { (steady state) }\end{array}$ & $14(13.5-15) L^{c}$ & $1 \mathrm{I}-14 \mathrm{~L}$ \\
\hline & Metabolism location & Liver & None \\
\hline & Metabolites & I7-Desacetyl-rocuronium & None \\
\hline & & I6N-desally|-rocuronium & \\
\hline & Elimination route & Biliary and renal & Renal \\
\hline & Elimination half-life & $1.2(1.1-1.3)$ hours & I.8 (I-4) hours \\
\hline & Plasma clearance & $259(245-273) \mathrm{mL} / \mathrm{min}^{d}$ & $88(75-138) \mathrm{mL} / \mathrm{min}$ \\
\hline & Protein binding & $30 \%$ & $0 \%$ \\
\hline \multirow[t]{6}{*}{ Chemical and physical } & Molecular weight & $609.7 \mathrm{~g} / \mathrm{mol}$ & $2,178 \mathrm{~g} / \mathrm{mol}$ \\
\hline & Water solubility & $0.14 \mathrm{mg} / \mathrm{L}$ & $31,470 \mathrm{mg} / \mathrm{L}$ \\
\hline & Octanol-water & 0.5 at $20^{\circ} \mathrm{C}$ & -12 at $25^{\circ} \mathrm{C}$ \\
\hline & partition coefficient & & \\
\hline & $\log S^{\S}$ & -6.63 & -1.84 \\
\hline & $\log P^{\neq}$ & 1.66 & 0.85 \\
\hline
\end{tabular}

Notes: ${ }^{a, b}$ Data obtained from summaries of product characteristics ${ }^{37,75}$; and personal communication from Merck \& Co., Inc., Medical Division (November $201 \mathrm{I}$ to August 2017). c, dVolume of distribution $(0.203 \text { [0.193-0.214] L/ } / \mathrm{kg})^{\mathrm{c}}$ and plasma clearance (3.7 [3.5-3.9] $\left.\mathrm{mL} \cdot \mathrm{kg} / \mathrm{min}\right)^{\mathrm{d}} \mathrm{calculated} \mathrm{for} \mathrm{an} \mathrm{adult} \mathrm{weighing} 70 \mathrm{~kg}$. ${ }^{\S}$ Logarithm (base 10) of water solubility (S) obtained with ALOGPS program. Hydrophilicity increases as the value of log $\mathrm{S}$ increases. ${ }^{\ddagger}$ Logarithm (base 10 ) of the octanol-water partition coefficient $(P)$, defined as the ratio of the compound's octanol phase:aqueous phase concentrations obtained with ALOGPS 2 . It is a measure of molecular hydrophobicity. Hydrophobicity increases as the value of $\log P \geq 0$ increases.

age: from $2.3(2-2.6)$ minutes for younger adults to 2.6 (2.3-2.9) minutes for elderly adults and 3.6 (3.1-4.1) minutes for old/elderly adults. ${ }^{45}$ Recovery of TOF ratio to 0.9 was estimated to be 0.7 minutes faster $(P=0.022)$ in younger adults compared with patients aged $\geq 65$ years (younger adult vs elderly and old/elderly groups combined: 2.3 [2-2.6] minutes vs 2.9 [2.7-3.2] minutes). Sugammadex was well tolerated, and no episodes of recurarization occurred. ${ }^{45}$ Similarly, in a study of 17 patients undergoing electroconvulsive therapy with propofol anesthesia, Kadoi et al found a significant difference in time to recovery to a TOF of 0.9 between eight young patients (aged $\leq 50$ years) and nine elderly patients (aged $\geq 70$ years) (403 \pm 37 seconds vs $443 \pm 36$ seconds, $P<0.05)$ after $8 \mathrm{mg} / \mathrm{kg}$ sugammadex in the presence of moderate rocuronium-induced NMB. ${ }^{48}$

More recently, in a prospective clinical trial, Yazar et al investigated the effect of sugammadex $2 \mathrm{mg} / \mathrm{kg}$ on duration of recovery from moderate rocuronium-induced NMB in elderly patients undergoing sevoflurane anesthesia. ${ }^{44}$ They found that the median (range) time from $\mathrm{T}_{2}$ to TOF ratio of 0.9 with sugammadex was 3.27 (1.41-5.37) minutes in younger elderly adults (aged 65-74 years) and 5.5 (2.47-9.54) minutes in older elderly patients (aged $\geq 75$ years) $(P<0.001) .{ }^{44}$

In a comparative, open-label study, Suzuki et al evaluated $4 \mathrm{mg} / \mathrm{kg}$ sugammadex, administered for reversal of deep rocuronium-induced NMB, in a group of elderly patients (aged $\geq 70$ years) versus younger patients (aged $20-50$ years) undergoing sevoflurane anesthesia. ${ }^{46}$ Recovery of TOF ratio to 0.9 was significantly slower in the older group than in the younger group (mean [SD] 3.6 [0.7] vs 1.3 [0.3] minutes, $P<0.0001)$. There were no clinical events attributable to recurarization. ${ }^{46}$ Similarly, Yamamoto et al found that time to a TOF ratio of 1 after sugammadex $4 \mathrm{mg} / \mathrm{kg}$ was significantly longer in patients aged $\geq 70$ years than in patients aged 20-60 years (mean SD 177.6 [42.8] vs 119.9 [9.4] seconds, $P<0.0001) .{ }^{49}$

The findings of all these studies reflect the role of agerelated physiologic changes, particularly at muscles and NM junctions (eg, decreased muscle blood flow), as well as age-related effects on the pharmacokinetics and pharmacodynamics of NMBAs, in slowing the reversal of rocuroniuminduced NMB by sugammadex in elderly patients. ${ }^{44-46,48,49}$ To better comprehend the magnitude of the delay in reversal of rocuronium-induced NMB by sugammadex in elderly compared with younger subjects, we performed a metaanalysis of English-language controlled trials investigating this aspect (Table 3 ). The meta-analysis of selected studies found a significant $(P=0.0036)$ mean difference $(95 \% \mathrm{CI})$ of 1.37 (0.45-2.3) minutes between elderly and younger subjects in reversal time of rocuronium-induced NMB by sugammadex, a delay in the elderly that should be considered in clinical practice (Figure 1).

Age-related decreases in total body water and lean body mass, with a smaller apparent volume of distribution for sugammadex, may predispose the elderly to increased plasma concentrations of the drug after intravenous administration. However, this does not appear to reduce the safety of sugammadex, which is generally well tolerated in patients also at higher doses. ${ }^{50}$ In a randomized multicenter, safety assessor-blinded, parallel-group, activecontrol Phase III trial investigating the reversal of profound $\mathrm{NMB}$ by $16 \mathrm{mg} / \mathrm{kg}$ sugammadex administered 3 minutes 


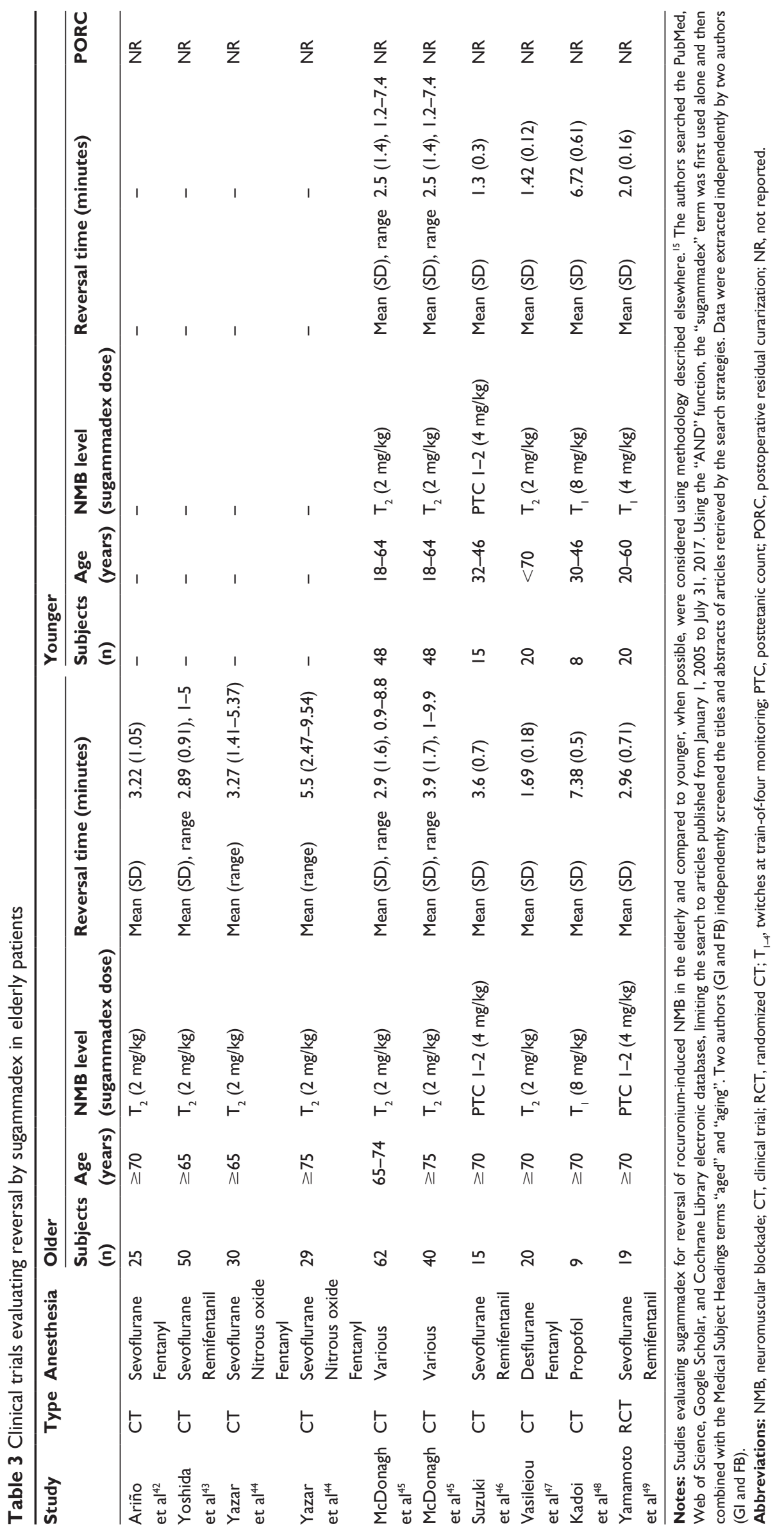




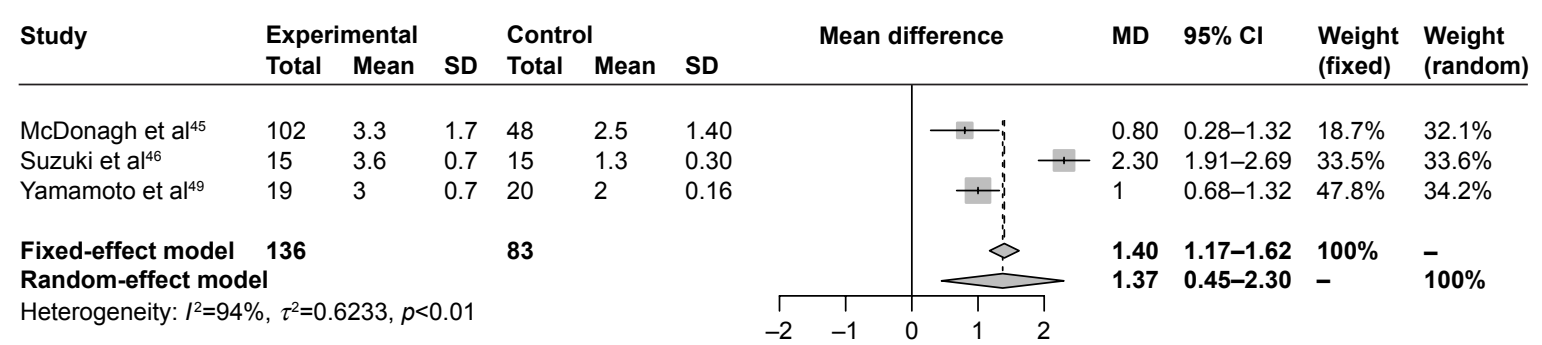

Figure I Forest plot of meta-analysis of data from controlled studies of sugammadex for reversal of rocuronium-induced NMB in elderly compared with younger subjects. Notes: Inclusion and exclusion criteria, search strategy, and methodology described elsewhere ${ }^{15}$ and in Table 3. To analyze reversal times (expressed in minutes), means and SDs were compared by mean difference (MD) and $95 \% \mathrm{Cl}$ for continuous-outcome data. ${ }^{15}$ Meta-analysis was performed using both random- and fixed-effect models. The random-effect model was computed with inverse-variance weighting using the DerSimonian-Laird method to account for heterogeneity. Heterogeneity across studies was tested using the $l^{2}$ statistic. ${ }^{15} P^{2}>50 \%$ was considered substantial. ${ }^{15}$ Experimental, sugammadex at $2^{45}$ or $4 \mathrm{mg} / \mathrm{kg}^{46,49}$ administered for reversal of moderate or deep rocuroniuminduced NMB, respectively, in the elderly; controls, sugammadex at 2 or $4 \mathrm{mg} / \mathrm{kg}$ administered for reversal of moderate or deep rocuronium-induced $\mathrm{NMB}$, respectively, in younger subjects. Meta-analysis demonstrated a significant $\mathrm{MD}(95 \% \mathrm{Cl})$ of $\mathrm{I} .37(0.45-2.3)(\mathrm{P}=0.0036)$ in reversal time of rocuronium-induced $\mathrm{NMB}$ by sugammadex, delayed in elderly compared with younger subjects.

Abbreviation: NMB, neuromuscular blockade.

after $1.2 \mathrm{mg} / \mathrm{kg}$ rocuronium, Lee et al found no recurrence of NMB or serious adverse events related to study treatment. ${ }^{51}$ Moreover, in a randomized, double-blind, crossover, placebo-controlled, single-center study investigating 32, 64, and $96 \mathrm{mg} / \mathrm{kg}$ doses of sugammadex in 13 healthy adults, Peeters et al found that sugammadex was well tolerated in 12 of 13 subjects. When present, adverse events were generally mild, of limited duration, and more frequent at higher doses. The most common adverse event was dysgeusia, and there were no serious adverse events. One subject was withdrawn from the study after experiencing several adverse events following exposure to sugammadex, attributed to probable hypersensitivity to the drug. ${ }^{52}$

Sugammadex-induced hypersensitivity reactions, including anaphylaxis, have been reported with an incidence below $1 \%, 53,54$ and as with all drugs, they are of concern, considering that elderly patients are particularly vulnerable to adverse drug reactions. ${ }^{55}$ However, no sugammadex-induced hypersensitivity reactions were reported in the studies evaluating its efficacy and safety in elderly patients. ${ }^{42-49}$ Among 15 cases of hypersensitivity following sugammadex administration revised by Tsur and Kalansky, only one patient was aged $>65$ years. ${ }^{56}$ Miyazaki et al retrospectively investigated the incidence of potential sugammadex-induced anaphylaxis at a single center in Japan over a period of 3 years. The total number of patients who received sugammadex during the study period was 15,479 , and the incidence of anaphylaxis associated with sugammadex was $0.039 \%$ (95\% CI $0.014 \%-0.084 \%$ ). None of the six patients involved were aged $>65$ years. ${ }^{54}$ Therefore, drug-induced hypersensitivity reactions are possible, particularly during the critical 5-minute period immediately following sugammadex administration, ${ }^{56}$ but the risk of anaphylaxis associated with sugammadex seems to be a rare event in the elderly. $42-49,54,56$

\section{Influence of differential muscle sensitivity to NMBAs and anesthetic agents}

Other factors have been investigated in an effort to explain the delayed reversal time with aging, such as differential sensitivity of various muscles to NMBAs and the potential role of general anesthetic drugs. Among the typical NMmonitoring sites used during clinical anesthesia, the orbicularis oculi and adductor pollicis muscles are described as being sensitive to NMBAs. Maximum blockade is more profound, and the duration of action is longer at these muscles than at the more resistant muscles, such as the corrugator supercilii, laryngeal adductors, and diaphragm. ${ }^{57-60}$ Sugammadex, administered to reverse a rocuronium-induced NMB, showed different reversal profiles in muscles with different sensitivities to NMBAs. ${ }^{49}$ Yamamoto et al found that reversal time observed at the adductor pollicis was significantly longer in patients aged $\geq 70$ years than in patients aged $20-60$ years $(P<0.0001)$, but there was no difference according to age at the corrugator supercilii. ${ }^{49}$ The explanation for the latter finding is unclear, but may reflect preservation of functional muscle activity, blood flow, or both at the corrugator supercilii with advanced age. ${ }^{49}$

Propofol and inhalational anesthetics, such as sevoflurane or desflurane, are widely used for maintenance of anesthesia. In contrast to propofol, inhalational anesthetics enhance the effects of certain NMBAs, including rocuronium. They increase the intensity of $\mathrm{NMB},{ }^{61}$ and in some cases prolong the duration of action of rocuronium and time to recovery. ${ }^{61,62}$ However, sugammadex has been shown to be equally effective for reversing moderate and deep rocuronium-induced NMB during sevoflurane or propofol anesthesia. ${ }^{63,64}$ This suggests that sevoflurane does not pharmacodynamically inhibit chemical binding between rocuronium and sugammadex. ${ }^{64,65}$ 
Nevertheless, Dwyer and Howe showed that perfusion of forearm muscle and skin is maintained in patients aged 18-34 years, but not in patients aged 60-79 years, during anesthesia when receiving isoflurane at $0.8 \%-1.2 \%$ combined with nitrous oxide at $66 \%{ }^{66}$ This suggests that inhalational anesthesia may have some influence on slowing the recovery from NMB by sugammadex through further reducing cardiac output and muscle blood flow, both of which are already decreased with age. Changes in blood flow to peripheral tissues produced by volatile anesthetics may thereby contribute to age-related variations in recovery from rocuronium-induced NMB with sugammadex. ${ }^{46}$

\section{Dose considerations}

Based on the aforementioned findings and the physiologic changes that occur with aging, older patients may be expected to require a higher dose of sugammadex to achieve adequate recovery from NMB within a short time. ${ }^{67}$ In a study comparing 22 young (aged $20-40$ years) and 22 elderly (aged $\geq 70$ years) adults administered $4 \mathrm{mg} / \mathrm{kg}$ sugammadex to revert deep rocuronium-induced NMB (one to two posttetanic counts), Shin et al reported that the $\mathrm{ED}_{95}(95 \%$ CI) of sugammadex for adequate recovery within 2 minutes was $5.4(4.9-5.5) \mathrm{mg} / \mathrm{kg}$ in elderly adults and 4.4 (3.9-4.5) $\mathrm{mg} / \mathrm{kg}$ in young adults. ${ }^{67}$ Dose adjustments of sugammadex should thus be considered when rapid recovery from deep NMB is required in elderly adults. ${ }^{67}$

\section{Respiratory and cardiovascular dysfunction}

Aging affects respiratory and cardiovascular system and the elderly may present respiratory and cardiovascular diseases. However, there are no limitations on the use of sugammadex in the presence of age-related respiratory and/or cardiovascular dysfunction. In a randomized, multicenter, parallel-group, comparative, safety assessor-blinded study involving 77 patients with pulmonary disease, sugammadex was shown to be safe and effective for the reversal of rocuronium-induced NMB. ${ }^{68}$ Compared to neostigmine, sugammadex has been associated with significantly less risk of postoperative desaturation (RR 0.23 , 95\% CI 0.06-0.83) and need for transitory oxygen supplementation (RR 0.24 , 95\% CI 0.09-0.66) and (not significant) less risk of laryngospasm (RR 0.34, 95\% CI 0.07-1.65) and increased upper-airway secretion (RR 0.37, 95\% CI 0.09-1.59). ${ }^{69}$ Compared to neostigmine, sugammadex has been associated with a not significant greater risk of cough (RR 1.42, 95\% CI 0.42-4.81). ${ }^{69}$ Restoration of cough and swallowing reflexes is key to preventing pulmonary aspiration after anesthesia in the elderly. ${ }^{70}$ However, it is possible that the straining that occurs during coughing can be responsible for provoking reflux events and pulmonary aspiration. ${ }^{71}$ Awareness on this aspect is then important. ${ }^{70,71}$

In a randomized, safety assessor-blinded, placebocontrolled trial, Dahl et al found that sugammadex can be given safely and effectively for reversal of rocuroniuminduced NMB in patients with cardiovascular disease undergoing noncardiac surgery. ${ }^{72}$ Kizilay et al suggested that sugammadex might be preferable, as it provides more hemodynamic stability compared to neostigmine-atropine combination in cardiac patients (aged 18-75 years) undergoing noncardiac surgery. ${ }^{73}$ A significantly lower risk of bradycardia (RR 0.16, 95\% CI 0.07-0.34) and (not significant) lower risk of tachycardia (RR $0.44,95 \%$ CI 0.09-2.22) and supraventricular extrasystoles (RR $0.32,95 \% \mathrm{CI}$ 0.03-3.05) has been reported. ${ }^{69}$ Furthermore, sugammadex alone or in combination with rocuronium or vecuronium is not associated with QTc prolongation. ${ }^{74}$

\section{Liver and kidney dysfunction}

Unlike aminosteroid NMBAs, ${ }^{12,75}$ sugammadex is not metabolized by the liver, and age-related changes in liver function should not affect the drug's pharmacokinetic profile. ${ }^{37}$ By contrast, as sugammadex is primarily excreted in an unchanged form via urine within 24 hours at usual clinical doses (Table 2), ${ }^{37}$ its potential role in kidney function may be suspected, and alteration of the drug's pharmacokinetic profile may be expected with changes in kidney function. ${ }^{76-78}$

On the first aspect, considering that both acetylcholinesterase inhibitors $(-50 \%)$ and sugammadex $(\geq 95 \%)$ are excreted unchanged by the kidneys, Isik et al investigated the effects of neostigmine ( 25 patients) and sugammadex (25 patients) on kidney function by means of sensitive biomarkers (eg, cystatin C) after a surgical procedure under desflurane/opioid anesthesia. They found that both drugs may affect kidney function, but sugammadex had more tolerable effects than neostigmine. ${ }^{76}$

Age-associated loss of kidney function may affect the elimination of sugammadex. In patients with a creatinine clearance $<30 \mathrm{~mL} / \mathrm{min}$, sugammadex clearance is reduced by 17 -fold and elimination half-life by 15 -fold compared with patients without renal impairment. ${ }^{77}$ In a Phase III trial, Staals et al reported pharmacokinetic data obtained from 26 patients who received rocuronium at $0.6 \mathrm{mg} / \mathrm{kg}$ followed by a single dose of sugammadex at $2.0 \mathrm{mg} / \mathrm{kg}$ at reappearance of two twitches during TOF monitoring. Mean total plasma 
clearance of sugammadex was $5.5 \mathrm{~mL} / \mathrm{min}$ in patients with impaired renal function (creatinine clearance $<30 \mathrm{~mL} / \mathrm{min}$ ) and $95.2 \mathrm{~mL} / \mathrm{min}$ in normal controls $(P<0.05)$. Rocuronium clearance was also reduced: $41.8 \mathrm{~mL} / \mathrm{min}$ in patients with renal impairment and $167 \mathrm{~mL} / \mathrm{min}$ in controls $(P<0.05)$. Median percentages of administered sugammadex and rocuronium excreted in the urine over 72 hours were $29 \%$ and $4 \%$, respectively, in patients with renal impairment, in contrast to $73 \%$ and $42 \%$, respectively, over 24 hours in controls. ${ }^{78}$

By contrast, the efficacy of sugammadex is not altered by impaired renal function. After administration of $2 \mathrm{mg} / \mathrm{kg}$ sugammadex to reverse moderate rocuronium-induced NMB, the mean (SD) time to recovery of TOF ratio to 0.9 was 2 (0.72) minutes in 15 patients with impaired renal function and $1.65(0.63)$ minutes in 15 normal controls $(P>0.05)$. Furthermore, no block recurrence was observed.$^{75}$ Recently, Min et al published their results of an open-label, two-part, Phase I study of 18 adults with moderate (creatinine clearance $30-50 \mathrm{~mL} / \mathrm{min}$ ) or severe (creatinine clearance $<30 \mathrm{~mL} / \mathrm{min}$ ) renal impairment and healthy controls. ${ }^{79}$ After $4 \mathrm{mg} / \mathrm{kg}$ sugammadex, pharmacokinetic data showed that the mean sugammadex exposure (area under the plasma concentration vs time curve) in subjects with moderate and severe renal impairment was 2.42 and 5.42 times, respectively, that of healthy controls. Clearance decreased and apparent terminal half-life was prolonged with increasing renal dysfunction. There were no serious adverse events or episodes of recurarization. Therefore, dose adjustment of sugammadex is not required in patients with moderate renal impairment. ${ }^{66}$ However, current evidence evaluating safety is insufficient to support the use of sugammadex in patients with a creatinine clearance below $30 \mathrm{~mL} / \mathrm{min}^{77-79}$

\section{Conclusion}

In conclusion, aging is associated with certain changes in the pharmacokinetics of sugammadex when used in elderly patients. In patients aged $>65$ years, time to recovery from rocuronium-induced NMB after sugammadex administration is prolonged on average by 1-2 minutes compared to younger patients. However, this delayed reversal of rocuroniuminduced NMB is not associated with reduced efficacy of the drug or an increased risk of adverse effects in the elderly. Therefore, special dose recommendations have not been issued for older patients. However, if it is necessary to achieve adequate recovery of rocuronium-induced NMB in a short period, then a greater dose of sugammadex may be considered.

\section{Disclosure}

MC has received payments for lectures from Merck Sharp \& Dohme (MSD), Italy. The authors report no other conflicts of interest in this work.

\section{References}

1. Bloom DE, Chatterji S, Kowal P, et al. Macroeconomic implications of population ageing and selected policy responses. Lancet. 2015;385(9968):649-657.

2. Sear JW. Implication of aging on anesthetic drugs. Curr Opin Anaesthesiol. 2003;16(4):373-378.

3. Holt NF. Trends in healthcare and the role of the anesthesiologist in the perioperative surgical home: the US perspective. Curr Opin Anaesthesiol. 2014;27(3):371-376.

4. Priebe HJ. The aged cardiovascular risk patient. Br J Anaesth. 2000; 85(5):763-778

5. Plaud B, Debaene B, Donati F, Marty J. Residual paralysis after emergence from anesthesia. Anesthesiology. 2010;112(4):1013-1022.

6. Brull SJ, Kopman AF. Current status of neuromuscular reversal and monitoring: challenges and opportunities. Anesthesiology. 2017;126(1): 173-190.

7. Murphy GS, Szokol JW, Avram MJ, et al. Residual neuromuscular block in the elderly: incidence and clinical implications. Anesthesiology. 2015;123(6):1322-1336.

8. Stewart PA, Liang SS, Li QS, et al. The impact of residual neuromuscular blockade, oversedation, and hypothermia on adverse respiratory events in a postanesthetic care unit: a prospective study of prevalence, predictors, and outcomes. Anesth Analg. 2016;123(4):859-868.

9. Spanjer MR, Bakker NA, Absalom AR. Pharmacology in the elderly and newer anaesthesia drugs. Best Pract Res Clin Anaesthesiol. 2011; 25(3):355-365.

10. Strøm C, Rasmussen LS, Steinmetz J. Practical management of anaesthesia in the elderly. Drugs Aging. 2016;33(11):765-777.

11. Stankiewicz-Rudnicki M. Neuromuscular blockade in the elderly. Anaesthesiol Intensive Ther. 2016;48(4):257-260.

12. Lee LA, Athanassoglou V, Pandit JJ. Neuromuscular blockade in the elderly patient. J Pain Res. 2016;9:437-444.

13. Young WL, Matteo RS, Ornstein E. Duration of action of neostigmine and pyridostigmine in the elderly. Anesth Analg. 1988;67(8):775-778.

14. Young WL, Backus W, Matteo RS, Ornstein E, Diaz J. Pharmacokinetics and pharmacodynamics in the elderly. Anesthesiology. 1984; 61(3A):A300.

15. Carron M, Zarantonello F, Tellaroli P, Ori C. Efficacy and safety of sugammadex compared to neostigmine for reversal of neuromuscular blockade: a meta-analysis of randomized controlled trials. JClin Anesth. 2016;35:1-12

16. Carron M, Zarantonello F, Lazzarotto N, Tellaroli P, Ori C. Role of sugammadex in accelerating postoperative discharge: a meta-analysis. J Clin Anesth. 2017;39:38-44.

17. Prough DS. Anesthetic pitfalls in the elderly patient. J Am Coll Surg. 2005;200(5):784-794.

18. Enzinger C, Fazekas F, Matthews PM, et al. Risk factors for progression of brain atrophy in aging: six-year follow-up of normal subjects. Neurology. 2005;64(10):1704-1711.

19. Leenders KL, Perani D, Lammertsma AA, et al. Cerebral blood flow, blood volume and oxygen utilization: normal values and effect of age. Brain. 1990;113(Pt 1):27-47.

20. White PF, White LM, Monk T, et al. Perioperative care for the older outpatient undergoing ambulatory surgery. Anesth Analg. 2012;114(6): $1190-1215$.

21. Sprung J, Gajic O, Warner DO. Review article: age related alterations in respiratory function: anesthetic considerations. Can J Anaesth. 2006; 53(12):1244-1257.

22. Wei JY. Age and the cardiovascular system. NEngl J Med. 1992;327(24): 1735-1739. 
23. Gourtsoyiannis N, Prassopoulos P, Cavouras D, Pantelidis N. The thickness of the renal parenchyma decreases with age: a CT study of 360 patients. AJR Am J Roentgenol. 1990;155(3):541-544.

24. Fliser D, Zeier M, Nowack R, Ritz E. Renal functional reserve in healthy elderly subjects. Am Soc Nephrol. 1993;3(7):1371-1377.

25. Aymanns C, Keller F, Maus S, Hartmann B, Czock D. Review on pharmacokinetics and pharmacodynamics and the aging kidney. Clin J Am Soc Nephrol. 2010;5(2):314-327.

26. Schmucker DL. Age-related changes in liver structure and function: implications for disease? Exp Gerontol. 2005;40(8-9):650-659.

27. Wynne HA, Cope LH, Mutch E, Rawlins MD, Woodhouse KW, James OF. The effect of age upon liver volume and apparent liver blood flow in healthy man. Hepatology. 1989;9(2):297-301.

28. Vandervoort AA. Aging of the human neuromuscular system. Muscle Nerve. 2002;25(1):17-25.

29. Doherty TJ. Invited review: aging and sarcopenia. J Appl Physiol (1985). 2003;95(4):1717-1727.

30. Thomas DR. Loss of skeletal muscle mass in aging: examining the relationship of starvation, sarcopenia and cachexia. Clin Nutr. 2007; 26(4):389-399.

31. Olive JL, DeVan AE, McCully KK. The effects of aging and activity on muscle blood flow. Dyn Med. 2002;1:2.

32. Mangoni AA, Jackson SH. Age-related changes in pharmacokinetics and pharmacodynamics: basic principles and practical applications. Br J Clin Pharmacol. 2004;57(1):6-14.

33. Balice-Gordon RJ. Age-related changes in neuromuscular innervation. Muscle Nerve Suppl. 1997;5:S83-S87.

34. McMullen CA, Andrade FH. Functional and morphological evidence of age-related denervation in rat laryngeal muscles. J Gerontol A Biol Sci Med Sci. 2009;64(4):435-442.

35. Naguib M. Sugammadex: another milestone in clinical neuromuscular pharmacology. Anesth Analg. 2007;104(3):575-581.

36. Yang LP, Keam SJ. Sugammadex: a review of its use in anaesthetic practice. Drugs. 2009;69(7):919-942.

37. Bridion $100 \mathrm{mg} / \mathrm{mL}$ solution for injection [summary of product characteristics]. Available from: http://www.ema.europa.eu/docs/en_GB/ document_library/EPAR_-_Product_Information/human/000885/ WC500052310.pdf. Accessed August 15, 2017.

38. de Menezes CC, Peceguini LA, Silva ED, Simões CM. Use of sugammadex after neostigmine incomplete reversal of rocuroniuminduced neuromuscular blockade. Rev Bras Anestesiol. 2012;62(4): 543-547.

39. Sanchez ER, Torres CM, Calo PH, Jimenez I. Use of sugammadex on burn patients: descriptive study. Rev Bras Anestesiol. 2015;65(4): 240-243.

40. Green MS, Venkatesh AG, Venkataramani R. Management of residual neuromuscular blockade recovery: age-old problem with a new solution. Case Rep Anesthesiol. 2017;2017:8197035.

41. Shah D, Dharmarajah A. Use of sugammadex in an octagenerian [sic] with myaesthenia gravis undergoing emergency laporotomy [sic].J Clin Anesth. 2017;37:109-110.

42. Ariño JJ, Velasco JM, Martìn M, Gabaldón M, Calvet A, LópezTimoneda F. Efficacy and safety of sugammadex for reversal of rocuronium-Induced neuromuscular blockade in elderly patients. Eur J Anaesthesiol. 2011;28 (Suppl 48):220-221.

43. Yoshida F, Suzuki T, Kashiwai A, Furuya T, Konishi J, Ogawa S. Correlation between cardiac output and reversibility of rocuroniuminduced moderate neuromuscular block with sugammadex. Acta Anaesthesiol Scand. 2012;56(1):83-87.

44. Yazar E, Yilmaz C, Bilgin H, et al. A comparison of the effect of sugammadex on the recovery period and postoperative residual block in young elderly and middle-aged elderly patients. Balkan Med J. 2016; 33(2):181-187.

45. McDonagh DL, Benedict PE, Kovac AL, et al. Efficacy, safety and pharmacokinetics of sugammadex for the reversal of rocuronium-induced neuromuscular blockade in elderly patients. Anesthesiology. 2011; 114(2):318-329.
46. Suzuki T, Kitajima O, Ueda K, Kondo Y, Kato J, Ogawa S. Reversibility of rocuronium-induced profound neuromuscular block with sugammadex in younger and older patients. Br J Anaesth. 2011;106(6): 823-826.

47. Vasileiou I, Stratigopoulou P, Fotopoulou G, Dre K, Lampadariou A, Tsinari K. Evaluation of the reversal of neuromuscular blockade induced by rocuronium with sugammadex in elderly patients. Eur J Anaesthesiol. 2012;29 (Suppl 50):226.

48. Kadoi Y, Nishida A, Saito S. Recovery time after sugammadex reversal of rocuronium-induced muscle relaxation for electroconvulsive therapy is independent of cardiac output in both young and elderly patients. J ECT. 2013;29(1):33-36.

49. Yamamoto S, Yamamoto Y, Kitajima O, Maeda T, Suzuki T. Reversal of neuromuscular block with sugammadex: a comparison of the corrugator supercilii and adductor pollicis muscles in a randomized dose-response study. Acta Anaesthesiol Scand. 2015;59(7):892-901.

50. Abrishami A, Ho J, Wong J, Yin L, Chung F. Sugammadex, a selective reversal medication for preventing postoperative residual neuromuscular blockade. Cochrane Database Syst Rev. 2009;(4):CD007362.

51. Lee C, Jahr JS, Candiotti KA, Warriner B, Zornow MH, Naguib M. Reversal of profound neuromuscular block by sugammadex administered three minutes after rocuronium: a comparison with spontaneous recovery from succinylcholine. Anesthesiology. 2009;110(5): 1020-1025.

52. Peeters PA, van den Heuvel MW, van Heumen E, et al. Safety, tolerability and pharmacokinetics of sugammadex using single high doses (up to $96 \mathrm{mg} / \mathrm{kg}$ ) in healthy adult subjects: a randomized, double-blind, crossover, placebo-controlled, single-centre study. Clin Drug Investig. 2010;30(12):867-874.

53. Schaller SJ, Fink H. Sugammadex as a reversal agent for neuromuscular block: an evidence-based review. Core Evid. 2013;8:57-67.

54. Miyazaki Y, Sunaga H, Kida K, et al. Incidence of anaphylaxis associated with sugammadex. Anesth Analg. Epub 2017 Oct 19.

55. Davies EA, O'Mahony MS. Adverse drug reactions in special populations: the elderly. Br J Clin Pharmacol. 2015;80(4):796-807.

56. Tsur A, Kalansky A. Hypersensitivity associated with sugammadex administration: a systematic review. Anaesthesia. 2014;69(11): 1251-1257.

57. Hemmerling TM, Donati F. Neuromuscular blockade at the larynx, the diaphragm and the corrugator supercilii muscle: a review. Can J Anaesth. 2003;50(8):779-794.

58. Hemmerling TM, Schmidt J, Hanusa C, Wolf T, Schmitt H. Simultaneous determination of neuromuscular block at the larynx, diaphragm, adductor pollicis, orbicularis oculi and corrugator supercilii muscles. Br J Anaesth. 2000;85(6):856-860.

59. Suzuki T, Mizutani H, Miyake E, Fukano N, Saeki S, Ogawa S. Infusion requirements and reversibility of rocuronium at the corrugator supercilii and adductor pollicis muscles. Acta Anaesthesiol Scand. 2009;53(10):1336-1340.

60. Lee HJ, Kim KS, Jeong JS, Cheong MA, Shim JC. Comparison of the adductor pollicis, orbicularis oculi, and corrugator supercilii as indicators of adequacy of muscle relaxation for tracheal intubation. Br J Anaesth. 2009;102(6):869-874.

61. Wulf H, Ledowski T, Linstedt U, Proppe D, Sitzlack D. Neuromuscular blocking effects of rocuronium during desflurane, isoflurane, and sevoflurane anaesthesia. Can J Anaesth. 1998;45(6):526-532.

62. Lowry DW, Mirakhur RK, McCarthy GJ, Carroll MT, McCourt KC. Neuromuscular effects of rocuronium during sevoflurane, isoflurane, and intravenous anesthesia. Anesth Analg. 1998;87(4):936-940.

63. Maidatsi PG, Zaralidou AT, Gorgias NK, Amaniti EN, Karakoulas KA, Giala MM. Rocuronium duration of action under sevoflurane, desflurane or propofol anaesthesia. Eur J Anaesthesiol. 2004;21(10): 781-786.

64. Vanacker BF, Vermeyen KM, Struys MM, et al. Reversal of rocuronium-induced neuromuscular block with the novel drug sugammadex is equally effective under maintenance anesthesia with propofol or sevoflurane. Anesth Analg. 2007;104(3):563-568. 
65. Rex C, Wagner S, Spies C, et al. Reversal of neuromuscular blockade by sugammadex after continuous infusion of rocuronium in patients randomized to sevoflurane or propofol maintenance anesthesia. Anesthesiology. 2009;111(1):30-35.

66. Dwyer R, Howe J. Peripheral blood flow in the elderly during inhalational anaesthesia. Acta Anaesthesiol Scand. 1995;39(7):939-944.

67. Shin S, Han DW, Lee HS, Song MK, Jun EK, Kim SY. Elderly patients require higher doses of sugammadex for rapid recovery from deep neuromuscular block. Basic Clin Pharmacol Toxicol. 2016;118(6): $462-467$.

68. Amao R, Zornow MH, Cowan RM, Cheng DC, Morte JB, Allard MW. Use of sugammadex in patients with a history of pulmonary disease. J Clin Anesth. 2012;24(4):289-297.

69. Hristovska AM, Duch P, Allingstrup M, Afshari A. Efficacy and safety of sugammadex versus neostigmine in reversing neuromuscular blockade in adults. Cochrane Database Syst Rev. 2017;8:CD012763.

70. Ebihara S, Ebihara T, Kohzuki M. Effect of aging on cough and swallowing reflexes: implications for preventing aspiration pneumonia. Lung. 2012;190(1):29-33.

71. Smith JA, Houghton LA. The oesophagus and cough: laryngopharyngeal reflux, microaspiration and vagal reflexes. Cough. 2013; 9(1):12.

72. Dahl V, Pendeville PE, Hollmann MW, Heier T, Abels EA, Blobner M. Safety and efficacy of sugammadex for the reversal of rocuroniuminduced neuromuscular blockade in cardiac patients undergoing noncardiac surgery. Eur J Anaesthesiol. 2009;26(10):874-884.
73. Kizilay D, Dal D, Saracoglu KT, Eti Z, Gogus FY. Comparison of neostigmine and sugammadex for hemodynamic parameters in cardiac patients undergoing noncardiac surgery. J Clin Anesth. 2016;28: 30-35.

74. de Kam PJ, van Kuijk J, Prohn M, Thomsen T, Peeters P. Effects of sugammadex doses up to $32 \mathrm{mg} / \mathrm{kg}$ alone or in combination with rocuronium or vecuronium on QTe prolongation: a thorough QTe study. Clin Drug Investig. 2010;30(9):599-611.

75. Rocuronium [summary of product characteristics]. 2015. Available from: https://www.medicines.org.uk/emc/medicine/5166\#FORM. Accessed September 9, 2015.

76. Isik Y, Palabiyik O, Cegin BM, Goktas U, Kati I. Effects of sugammadex and neostigmine on renal biomarkers. Med Sci Monit. 2016; 22:803-809.

77. Staals LM, Snoeck MM, Driessen JJ, Flockton EA, Heeringa M, Hunter JM. Multicentre, parallel-group, comparative trial evaluating the efficacy and safety of sugammadex in patients with end-stage renal failure or normal renal function. Br J Anaesth. 2008;101(4):492-497.

78. Staals LM, Snoeck MM, Driessen JJ, et al. Reduced clearance of rocuronium and sugammadex in patients with severe to end-stage renal failure: a pharmacokinetic study. Br J Anaesth. 2010;104(1):31-39.

79. Min KC, Lasseter KC, Marbury TC, et al. Pharmacokinetics of sugammadex in subjects with moderate and severe renal impairment. Int $J$ Clin Pharmacol Ther. 2017;55(9):746-752.
Clinical Interventions in Aging

\section{Publish your work in this journal}

Clinical Interventions in Aging is an international, peer-reviewed journal focusing on evidence-based reports on the value or lack thereof of treatments intended to prevent or delay the onset of maladaptive correlates of aging in human beings. This journal is indexed on PubMed Central, MedLine,

\section{Dovepress}

CAS, Scopus and the Elsevier Bibliographic databases. The manuscript management system is completely online and includes a very quick and fair peer-review system, which is all easy to use. Visit http://www.dovepress. com/testimonials.php to read real quotes from published authors. 